\title{
Eye movements during the reading of compound words and the influence of lexeme meaning
}

\author{
Albrecht W. Inhoff, Matthew S. Stark, Matthew Solomon, and Lars Placke \\ State University of New York, Binghamton, New York
}

\begin{abstract}
We examined the use of lexeme meaning during the processing of spatially unified bilexemic compound words by manipulating both the location and the word frequency of the lexeme that primarily defined the meaning of a compound (i.e., the dominant lexeme). The semantically dominant and nondominant lexemes occupied either the beginning or the ending compound word location, and the beginning and ending lexemes could be either high- or low-frequency words. Three tasks were used-lexical decision, naming, and sentence reading - all of which focused on the effects of lexeme frequency as a function of lexeme dominance. The results revealed a larger word frequency effect for the dominant lexeme in all three tasks. Eye movements during sentence reading further revealed larger word frequency effects for the dominant lexeme via several oculomotor motor measures, including the duration of the first fixation on a compound word. These findings favor theoretical conceptions in which the use of lexeme meaning is an integral part of the compound recognition process.
\end{abstract}

Compound words are formed by combining free lexemes into a single lexicalized expression. Few rules govern this lexical-conceptual "evolution.” In English, lexicographers find new compounds by examining popular usage - that is, words used together relatively often to denote a specific concept. Most compounds become "solid"- that is, are written as spatially unified expressions - but others are written with a blank space between the lexeme constituents or are hyphenated. One central question in the study of compound recognition has been whether the spatial and conceptual unification of solid compounds is reversed during the recognition process - that is, whether the constituents of the compound are discerned and accessed before the overall word is recognized. The bulk of the available empirical evidence indicates that such decomposition indeed takes place.

Experimental effects of compound decomposition have been obtained when either individually presented compound words or words related to compound word primes were to be named or classified (see, e.g., Coolen, van Jaarsveld, \& Schreuder, 1991, 1993; Inhoff \& Topolski, 1994; Laudanna, Badecker, \& Caramazza, 1989; Libben, Derwing, \& de Almeida, 1999; Lima \& Pollatsek, 1983; Prinzmetal, 1990; Prinzmetal, Hoffman, \& Vest, 1991; Sandra, 1990; Shillcock, 1990; Taft, 1985; Taft \& Forster, 1976; van Jaarsveld \& Rattink, 1988; Zwitserlood, 1994). Decompositional effects have also been obtained when compound words were viewed during sentence reading (Andrews, Miller, \& Rayner, 2004; Bertram \& Hyönä, 2003; Hyönä \& Pollatsek, 1998; Inhoff, Briihl, \& Schwartz, 1996; Inhoff, Radach, \& Heller, 2000; Juhasz, 2007; Juhasz, Inhoff, \& Rayner, 2005; Juhasz, Starr, Inhoff, \& Placke, 2003; Pollatsek, Hyönä, \& Bertram, 2000). In Hyönä and Pollatsek's influential study, readers spent less time viewing spatially unified Finnish compounds with high-frequency beginning lexemes than viewing matched compounds with low-frequency beginning lexemes. The frequency of the beginning lexeme influenced compound reading at a relatively early stage; that is, the first-fixation duration was shorter when a solid compound contained a high-frequency beginning lexeme. A follow-up study, Pollatsek et al. (2000), further showed that both the word frequency of the second lexeme and the frequency of the full compound word influenced compound viewing and that these two frequency effects emerged at approximately the same time, after the first fixation on a compound word. Readers thus discern the constituent lexemes of spatially unified long Finnish compound words and use these lexemes progressively in a time-locked manner.

Decomposition of compound words may assist the accessing of orthographic word forms. The orthographic form of a constituent lexeme is less complex and is generally much more common and familiar than the orthographic form of the full compound. Lexical search that proceeds from relatively simple and familiar lexeme forms to the full compound form could thus be more effective than lexical search using only the full compound's orthographic form (Hyönä \& Pollatsek, 1998; Taft \& Forster, 1976). According to the length of the compound, access of the full form could then proceed via the first lexemefor instance, when the compound is relatively long - or via all constituent lexemes and the full word form - when a bilexemic compound is relatively short (Bertram \& Hyönä, 2003; Juhasz et al., 2003).

Lexeme constituents could also contribute to the specification of compound meaning. Generally, the meanings of

A.W. Inhoff, inhoff $@$ binghamton.edu 
both lexemes of a bilexemic compound word are directly related to the overall compound meaning. In these cases, the second lexeme typically defines the compound's category, and the first lexeme defines a subordinate categoryfor example, lamplight is light emanating from a lamp. Other types of lexeme-compound compositions do exist, however. Some compound words are semantically related to the meaning of just one lexeme - for example, jailbird is directly related to jail but not to bird - and in a small number, neither constituent lexeme is directly related to compound meaning - for example, the meaning of deadline is related neither to dead nor to line. In the literature, these three types of lexeme-compound relationships are generally referred to as transparent, partially opaque (or partially transparent), and opaque, respectively.

Virtually all studies that have examined the use of lexeme meaning during compound recognition have contrasted compound words with different degrees of semantic transparency (Jarema, Busson, Nikolova, Tsapkini, \& Libben, 1999; Libben, Gibson, Yoon, \& Sandra, 2003; Pollatsek \& Hyönä, 2005; Zwitserlood, 1994, Experiment 2). Tasks that involved the classification of single - generally primedwords showed robust transparency effects. In Zwitserlood's Experiment 2, for instance, transparent compounds primed words that were semantically related to the compound's constituent lexemes (e.g., teaspoon primed coffee and forkthe study was conducted in Dutch), as did partially opaque compounds (e.g., jailbird primed prison and feather). Opaque compounds, by contrast, did not prime words that were semantically related to their lexeme constituents (e.g., buttercup primed neither bread nor plate). According to these results, the meaning of individual lexemes does contribute to compound processing when there is some overlap between lexeme and compound meaning. However, compound meaning appears to dominate and suppress lexeme meaning in the absence of such overlap.

The effects of semantic transparency in the lexical decision task stand in stark contrast to the absence of such effects with spatially unified compounds in some reading studies (Frisson, Niswander-Klement, \& Pollatsek, 2008; Pollatsek \& Hyönä, 2005). Pollatsek and Hyönä examined eye movements during the reading of bilexemic Finnish compounds with a transparent lexeme-compound relationship (e.g., altarpiece) and with an opaque or partially opaque relationship (e.g., blood enemy; the two lexemes form a spatially unified compound in Finnish). As in their earlier work, Pollatsek and Hyönä also manipulated the word frequency of the beginning lexeme to determine whether both types of compound words were parsed into constituent lexemes. Examination of compound viewing durations revealed the familiar signature of orthographic decomposition; that is, readers spent less time gazing at a compound word when it contained a high-frequency rather than a low-frequency beginning lexeme. Notably, the lexeme frequency effect was equal in size for transparent and opaque compounds, indicating that the decomposition of compound words was not influenced by the semantic transparency of constituent lexemes.

Furthermore, the transparency of the lexeme-compound relationship was of little consequence for overall com- pound reading. The durations of the first fixations on the two types of compound words were roughly equivalent, as were their cumulated viewing times (gaze durations). Both types of compound words also received an equal number of fixations during sentence reading, and the semantic relationship between the compound and its constituent lexemes influenced neither the relative frequency of regressions nor the time spent reading the posttarget word that immediately followed the compound word in the sentence.

Ratings showed that transparent compounds were judged to be much more transparent than (partially) opaque compounds, with mean ratings of 1.6 and 5.0 on a 7-point rating scale (where 1 indicated total transparency), respectively. Supplementary regression analyses that included transparency ratings of items as a predictor variable also failed to obtain effects of semantic transparency. Although post hoc analyses indicated that lexeme meaning may have been used for some items with a lowfrequency beginning lexeme, Pollatsek and Hyönä (2005) concluded that the orthographic form of the full compound was parsed into lexeme constituents and that these constituents were used for lexical access, but typically not for the specification of compound meaning.

Frisson et al. (2008) showed that the effect generalizes across languages. The transparency of spatially unified English compound words influenced neither their gaze duration nor the rate of regressions off compound words, again indicating that lexeme meaning does not influence the accessing of compound meaning. Juhasz (2007), who manipulated the frequency of the beginning and ending lexemes of transparent and opaque compounds, did obtain a robust transparency effect, with longer gaze durations for opaque compounds, but the effect of transparency combined additively with the effects of beginning and ending lexeme frequency. Transparent and opaque compound words were therefore assumed to be subject to lexical decomposition, and specification of compound meaning appeared to be independent of the meanings of lexeme constituents.

Extending earlier studies of compound processing in reading (Frisson et al., 2008; Juhasz, 2007; Pollatsek \& Hyönä, 2005), the present study used a novel manipulation to examine the influence of lexeme meaning on compound processing. Specifically, we used two types of compound words, one whose meaning was primarily defined by the beginning lexeme - for example, humankind - and another whose meaning was primarily defined by the ending lexeme-for example, handbook. In the following discussion, we refer to these two compound types as "headed"1 and "tailed," respectively. Following earlier work with Finnish compounds (Bertram \& Hyönä, 2003; Hyönä \& Pollatsek, 1998; Pollatsek \& Hyönä, 2005; Pollatsek et al., 2000) and English compounds (Andrews et al., 2004; Frisson et al., 2008; Juhasz, 2007; Juhasz et al., 2003), we also manipulated the word frequencies of a bilexemic compound's constituent lexemes, and we considered lexeme frequency effects as the signature of orthographic decomposition. Word frequency effects are greatly reduced when word meaning is irrelevant (Rayner 
\& Fischer, 1996; Rayner \& Raney, 1996), revealing a close relationship between the size of the effect of word frequency and the use of word meaning. Furthermore, Juhasz et al. (2003) obtained larger word frequency effects for the ending lexeme than for the beginning lexeme of transparent compound words in reading, naming, and lexical decision tasks; they attributed this effect to the larger role of the ending lexeme in the specification of transparent compound meaning. Although Juhasz (2007) did not obtain a larger ending than beginning lexeme effect, this could have resulted from the inclusion of opaque compounds, whose ending lexeme is often unrelated to compound meaning. Assuming that lexeme meaning influences compound recognition, we predicted that headed compounds would yield a larger word frequency effect for the beginning lexeme and that tailed compounds would yield a larger word frequency effect for the ending lexeme. To examine the influence of task demands, compound recognition was examined using lexical decision, naming, and sentence reading tasks.

\section{EXPERIMENT 1 Lexical Decision Iask}

\section{Method}

Participants. Thirty-one undergraduate students at the State University of New York at Binghamton participated for experimental course credit. All participants were native speakers of English and were naive about the purpose of the experiment.

Apparatus. Text was presented on a CRT monitor in light green on a black background. Head position was not restrained, but a typical response posture yielded a monitor-to-eye distance of approximately $80 \mathrm{~cm}$; at this distance, each character of text subtended approximately $1 / 3$ of a degree of visual angle. A keyboard was used to record response latencies. The " $z$ " key was used to denote "word" responses, and the "/" key to denote "nonword" responses.

Materials. The compound target words consisted of 80 bimorphemic compound words that were selected using the CELEX database for English (see the Appendix). Of these 80 compounds, 40 were classified as "headed" compounds, and the remaining 40 were classified as "tailed" compounds.

The classification of target compounds into headed and tailed followed a norming study with a much larger pool of items, consisting of 390 compound words. Thirteen native English speakers were asked to rate whether the meaning of a given compound was more closely related to the first or second constituent lexeme. These ratings were made on an 11-point scale ranging from 0 to 10 . A 0 rating denoted that the meaning of the compound was solely associated with the meaning of the first constituent lexeme, whereas a rating of 10 denoted that the meaning of the compound was solely associated with that of the second constituent lexeme. Compounds were considered headed when their mean rating was less than 4.0 (the overall mean was $3.34, S D=0.62$ ). Compounds were considered tailed if their mean rating was larger than 6.0 (the overall mean was 7.18, $S D=0.69$ ).

We also considered the individual lexeme frequencies in the item selection process. Half of the selected compound words contained an initial lexeme with a relatively high word frequency; the other half, a beginning lexeme with a relatively low word frequency. Orthogonally, the frequency of occurrence for compounds' ending lexemes was either high or low. Manipulation of the beginning and ending lexeme word frequencies thus resulted in four groups nested within both headed and tailed compound types: high-high (HH), high-low (HL), low-high (LH), and low-low (LL). Collapsed across headed and tailed compounds, the mean word frequencies of the beginning and ending lexemes of $\mathrm{HH}, \mathrm{HL}, \mathrm{LH}$, and LL compounds were $257-279,243-5,7-282$, and 5-5, respectively. Broken down by compound types, the lexeme frequencies of headed $\mathrm{HH}, \mathrm{HL}$, LH, and LL compounds were 239-289, 230-5, 7-266, and 5-4, respectively, whereas the frequencies of tailed $\mathrm{HH}, \mathrm{HL}, \mathrm{LH}$, and LL compounds were 275-269, 255-6, 6-298, and 5-5, respectively. Moreover, the mean word frequencies for high- and low-frequency constituents were statistically equivalent for headed and tailed compounds, with respective means of 256.1 versus 5.5 words per million for headed compounds and 274.3 versus 5.7 words per million for tailed compounds.

The different types of compound were also fully matched on fullword frequency. Collapsed across headed and tailed compounds, the mean word frequencies for the full forms of $\mathrm{HH}, \mathrm{HL}, \mathrm{LH}$, and LL compounds were equivalent, amounting to 3, 2, 2, and 1 words per million, respectively (for headed, $2,3,2$, and 0.4 , respectively; for tailed, 4, 0.5, 2, and 1, respectively). Collapsed across lexeme frequencies, overall frequencies for headed and tailed compounds were also equivalent (both means were 1.8 words per million). We also sought to match the different types of compound words on familiarity. This was assessed by 13 native English speakers, who were asked to rate their familiarity with a compound on an 11-point scale ranging from 0 to 10 , where a rating of 0 denoted a compound that was not at all familiar, whereas a rating of 10 denoted a compound that was highly familiar. Headed compounds had a mean familiarity rating of $9.0(S D=1.3)$, whereas tailed compounds had a mean familiarity rating of $8.9(S D=1.5)(t<1)$. Collapsed across headed and tailed compounds, the mean familiarity ratings for $\mathrm{HH}, \mathrm{HL}, \mathrm{LH}$, and LL compounds were equivalent, amounting to 9.2, 9.0, 8.8, and 8.9 , respectively (for headed, 9.3, 9.7, 8.8, and 8.2, respectively; for tailed, 9.0, 8.3, 8.9, and 9.6, respectively).

We also successfully matched the different compound words on length. All compounds were 8-11 characters long, and the mean word lengths were equated for headed and tailed compounds (both means were 9.1 characters). Word lengths for beginning and ending lexemes were also equivalent for headed and tailed compounds, amounting to 4.8 and 4.3 characters, respectively, for headed compounds and 4.5 and 4.6 characters, respectively, for tailed compounds. The relatively comprehensive matching of compound words also incurred a potential cost: Six lexemes occurred in two compound words, and one lexeme occurred in three compound words. The vast majority of lexemes (152) occurred, however, just once in the set of target words. To minimize any potential effects of lexeme repetition, compounds that shared a lexeme never followed each other in the experiment. Moreover, the experiment included filler items and pseudowords. Fillers were 80 monomorphemic words (8-11 characters long) whose frequencies and lengths were matched to those of the compounds (mean word frequency was 8.2 words per million, mean word length was 9.6 characters)

Eighty pseudoword compound targets (combinations of orthographically legal words and orthographically legal nonwords) were created by modifying 80 additional compound words. These items were changed to orthographically legal pseudoword compounds by replacing either one or two letters of the first or second constituent lexeme-for example, darkroom was changed to daukroom and paperback was changed to paperbesk. As with the headed and tailed compound stimuli, the lexeme frequencies of the additional compounds were orthogonally manipulated, such that each set of 40 pseudoword compounds consisted of $10 \mathrm{HH}, 10 \mathrm{HL}, 10 \mathrm{LH}$, and 10 LL compounds. Hence, although one lexeme constituent of each pseudoword compound was changed to an orthographically legal nonword, the other constituent was still either a high- or lowfrequency word. The lengths and frequencies of these constituent lexemes were matched to the constituents of the headed and tailed compounds.

Procedure. Participants were tested individually in a darkened room. Upon being seated in front of the CRT, participants were instructed to press the " $\mathrm{z}$ " key on the keyboard if the stimulus they saw was a nonword and to press the "/" key if the stimulus was a 
word. Before beginning the experiment, the participants completed a set of 20 practice trials, and once these practice trials were completed, they began the experiment. The order of target items was randomized. At the beginning of each trial, a central fixation cross appeared for $500 \mathrm{msec}$. Following the presentation of the fixation cross, each stimulus was presented after a delay of $500 \mathrm{msec}$, in uppercase letters centered around the position of the previously shown fixation marker. The stimulus disappeared once the participant had made a response by pressing one of two flanker buttons, and a new trial began after a delay of $750 \mathrm{msec}$. If a participant did not respond within $1,500 \mathrm{msec}$, the stimulus disappeared and that trial was eliminated.

Design and Data analyses. A single list was constructed containing all words and nonwords to be classified. The ordering of the four types of compound words with control words, filler words, and nonwords was randomized. Trials in which a participant pressed a key other than "z" or "/" were excluded from the analysis, resulting in the elimination of $5.4 \%$ of the data. Lexical decision times (LDTs) that were three standard deviations above $(1,305.4 \mathrm{msec})$ or below $(171.6 \mathrm{msec})$ the mean were excluded, resulting in the elimination of an additional $4.9 \%$ of the reaction time data, as were trials with a decision error.

Although the headed and tailed compounds were well matched on a number of linguistic dimensions, one type of compound might nevertheless have been more difficult to process than the other, and this could have influenced the expression of lexeme frequency effects. A first set of analyses therefore examined the effects of beginning and ending lexeme frequencies for headed and tailed compounds separately via 2 (word frequency of the first lexeme) $\times 2$ (word frequency of the second lexeme) ANOVAs. This analysis was followed by additional $2 \times 2 \times 2$ ANOVAs that included compound type as a factor. Error variability was computed over participants and items, with all independent variables constituting within-participants factors in the $F_{1}$ analyses and between-items factors in the $F_{2}$ analyses.

\section{Results}

LDTs and error rates as a function of the compound type and the word frequencies of beginning and ending lexemes are shown in Table 1.

Classification of headed compounds was $69 \mathrm{msec}$ shorter when the beginning lexeme was a high-frequency word than when it was a low-frequency word $\left[F_{1}(1,31)=\right.$ $\left.68.88, p<.01 ; F_{2}(1,36)=11.76, p<.01\right]$. Ending lexeme frequency also influenced the LDTs of headed compounds, which were $43 \mathrm{msec}$ shorter when the ending lexeme was a high-frequency word. This effect was significant over participants $\left[F_{1}(1,31)=28.82, p<.01\right]$ but not over items $\left[F_{2}(1,36)=2.16, p<.16\right]$. The interaction of beginning and ending lexeme frequency was not significant $\left(F_{1}\right.$ and $\left.F_{2}<1\right)$

The beginning lexeme effect was much less stable in tailed compounds, with LDTs only $22 \mathrm{msec}$ shorter when the beginning lexeme was a low-frequency word $\left[F_{1}(1,31)=11.77, p<.01 ; F_{2}(1,36)=1.45, p<.24\right]$.

Table 1

Mean Lexical Decision Latencies (in Milliseconds) and Error Rates (\%) for Experiment 1 As a Function of Compound Type

\begin{tabular}{|c|c|c|c|c|c|c|c|c|}
\hline \multirow{2}{*}{$\begin{array}{c}\text { Lexeme } \\
\text { Frequency }\end{array}$} & \multicolumn{4}{|c|}{ Headed } & \multicolumn{4}{|c|}{ Tailed } \\
\hline & $M$ & $S E$ & Err & $S E$ & $M$ & $S E$ & Err & $S E$ \\
\hline $\mathrm{HH}$ & 663 & 16 & 5 & 1 & 672 & 16 & 5 & 1 \\
\hline HL & 705 & 13 & 3 & 0.5 & 751 & 19 & 13 & 1 \\
\hline LH & 730 & 17 & 13 & 1 & 700 & 16 & 7 & 1 \\
\hline LL & 788 & 21 & 23 & 2 & 746 & 16 & 9 & 1 \\
\hline
\end{tabular}

Ending lexeme frequency exerted, by contrast, a profound influence on lexical decision latencies, with substantially shorter LDTs $(57 \mathrm{msec})$ when this lexeme was a highfrequency word. The ending lexeme effect was significant over both participants $\left[F_{1}(1,31)=46.72, p<.01\right]$ and items $\left[F_{2}(1,36)=8.39, p<.01\right]$. The interaction of beginning and ending lexeme frequency was not significant $\left[F_{1}(1,31)=1.68, p<.21 ; F_{2}<1\right]$.

The combined $2 \times 2 \times 2$ ANOVA of beginning and ending lexeme frequency effects for headed and tailed compounds revealed almost identical LDTs for headed and tailed compounds (722 and $717 \mathrm{msec}$, respectively; $F_{1}$ and $F_{2}<1$ ). The three-way interaction of beginning and ending lexeme frequency with compound type approached significance over participants $\left[F_{1}(1,30)=2.44, p<\right.$ .13] but not over items $\left(F_{2}<1\right)$. The beginning lexeme frequency effect was larger and more robust for headed than for tailed compounds, and the corresponding twoway interaction was reliable $\left[F_{1}(1,30)=30.89, p<.01\right.$; $\left.F_{2}(1,72)=3.25, p<.08\right]$. Even though ending lexeme effects were numerically larger for tailed than for headed compounds, there was no corresponding statistical twoway interaction of compound type with ending lexeme effect $\left(F_{1}\right.$ and $\left.F_{2}<1\right)$.

The pattern of error data was similar to that for the LDT data. For headed compounds, participants made substantially fewer errors when the beginning lexeme was a highfrequency word than when it was a low-frequency word, with means of $4 \%$ and $18 \%$, respectively $\left[F_{1}(1,30)=\right.$ $\left.61.33, p<.01 ; F_{2}(1,36)=7.34, p<.02\right]$. A smaller effect emerged for the ending lexeme, with means of $9 \%$ and $13 \%$ when the lexeme was a high- or a low-frequency word, respectively $\left[F_{1}(1,31)=6.47, p<.01\right.$, but $\left.F_{2}<1\right]$. The interaction between beginning and ending lexeme frequency, which was due to an elevated error rate for LL compounds, was also significant over participants $\left[F_{1}(1,31)=21.55, p<.01\right]$ but not over items $\left[F_{2}(1,36)=\right.$ $1.23, p<.28]$.

Once more, the effect pattern was reversed for tailed compounds. The word frequency of compounds' beginning lexemes had little effect on error rate (both $F_{\mathrm{S}}<1$ ); the ending lexeme, by contrast, was associated with fewer errors when it was a high-frequency word than when it was a low-frequency word, with error rates of $6 \%$ and $11 \%$, respectively $\left[F_{1}(1,30)=13.96, p<.01 ; F_{2}(1,36)=1.43\right.$, $p<.28]$. The interaction was significant over participants $\left[F_{1}(1,30)=5.09, p<.01\right]$ but not over items $\left(F_{2}<1\right)$. However, this time, the interaction was due to a higher error rate for HL compounds (see Table 1).

The joint analysis of beginning and ending lexeme effects as a function of compound type revealed 3\% more errors for headed compounds, and the corresponding main effect was reliable over participants $\left[F_{1}(1,30)=23.84, p<\right.$ $.01]$ but not over items $\left(F_{2}<1\right)$. The $2 \times 2 \times 2$ interaction of compound type with beginning and ending lexeme frequency was highly significant over participants, with more errors when the beginning lexeme of headed compounds was a low-frequency word and when the ending lexeme of tailed compounds was a low-frequency word $\left[F_{1}(1,30)=\right.$ $25.38, p<.01]$; but again the interaction was not signifi- 
cant over items $\left[F_{2}(1,72)=1.80, p<.19\right]$. As in the LDT data, error rates revealed a robust two-way interaction, with headed but not tailed compounds yielding a robust effect of beginning lexeme frequency $\left[F_{1}(1,30)=43.47, p<.01\right.$; $\left.F_{2}(1,72)=4.85, p<.05\right]$; the complementary two-way interaction of compound type with ending lexeme frequency failed to approach significance, however $\left(F_{1}\right.$ and $\left.F_{2}<1\right)$.

\section{Discussion}

LDTs and error rates showed sizable effects of lexeme frequency. This signature effect of orthographic decomposition is in general agreement with the results of earlier reading experiments, thus indicating that compound words are also parsed into constituent lexemes in the lexical decision task. Critically, the data also showed a systematic increase in the size of the word frequency effect for the meaningdominant lexeme in the LDT and error data, with somewhat larger and more reliable effects of the beginning lexeme. The meaning of individual lexemes was thus activated, and it contributed to compound processing.

The influence of lexeme dominance on the magnitude of the lexeme frequency effect was much more robust when error variance was computed over participants than when it was computed over items. This discrepancy is likely due to differences within the experimental design and in the resulting statistical power of the comparisons. $F_{1}$ statistics were computed using a within-participants design; $F_{2}$ statistics, by contrast, used a more conservative betweenitems design. Moreover, the pool of items in each of the four experimental conditions was relatively small $(n=10)$, further diminishing the statistical power of the item-based comparisons. It could be argued that lexeme dominance effects were present but were confined to a small subset of items (mean items LDTs are shown in the Appendix). An inspection of item LDTs did not reveal a principled subset of items, however, that could have caused the absence of robust meaning dominance effects in the items analyses.

A potential shortcoming of the lexical decision task is that it can induce task-specific response strategies. All pseudocompounds contained a legal and an illegal lexeme, which could have resulted in the parsing of targets into lexeme constituents and in the use of phonological and/or orthographic lexeme forms for lexical decision. Such a search strategy could have decreased lexeme dominance effects overall and undermined their robustness in the items analyses. Experiment 2 used another word recognition task, word naming, to minimize this potential word-nonword discrimination strategy. Pseudowords were removed from the item pool, thus discouraging the search for pseudolexeme constituents.

\section{EXPERIMENT 2 Naming Task}

\section{Method}

Participants. Thirty State University of New York undergraduates participated for experimental course credit. All were native speakers of English and were naive about the purpose of the experiment.

Apparatus and Materials. The same display method was used as in Experiment 1. Naming times were recorded to the nearest mil- lisecond. The microphone and the monitor were positioned so that a typical response posture again yielded a monitor-to-eye distance of approximately $80 \mathrm{~cm}$. The same materials were used as in Experiment 1 , except that all pseudowords were removed from the item set.

Procedure. The procedure of Experiment 2 was similar to that of Experiment 1, except that the lexical decision task was replaced with a target naming task. Throughout the experiment, an experimenter was present to record mispronunciations and instances in which the microphone was set off prematurely because of noise.

Design and Data analyses. Mispronunciations and cases in which the microphone was activated prematurely were excluded from the analyses, resulting in the elimination of $4.8 \%$ of the data. In addition, naming times that were three standard deviations above $(1,235 \mathrm{msec})$ or three standard deviations below $(75 \mathrm{msec})$ the mean were also excluded from the analyses, resulting in the elimination of an additional $1.6 \%$ of the data. Two compounds (windowpane and windowsill) were also eliminated from the analysis because of the computer's difficulty in detecting the onset of these words' pronunciations (i.e., the /w/ sound was too soft).

The naming times for headed and tailed compounds were subjected to a 2 (beginning lexeme frequency: high vs. low) $\times 2$ (ending lexeme frequency: high vs. low) ANOVA in a first analysis and to combined 2 (compound type) $\times 2$ (beginning lexeme) $\times 2$ (ending lexeme) follow-up ANOVAs. Again, error variance was computed over participants $\left(F_{1}\right)$ and items $\left(F_{2}\right)$.

\section{Results}

Naming latencies as a function of compound type are shown in Table 2.

For headed compounds, the data revealed a robust beginning lexeme effect, with naming latencies $47 \mathrm{msec}$ longer when the beginning lexeme was a low-frequency word than when it was a high-frequency word $\left[F_{1}(1,29)=35.35\right.$, $\left.p<.01 ; F_{2}(1,34)=6.77, p<.025\right]$. Ending lexemes also influenced the naming of headed compounds, with naming latencies $28 \mathrm{msec}$ longer when the ending lexeme was a low-frequency word. The ending lexeme effect was significant over participants $\left[F_{1}(1,29)=34.14, p<.01\right]$ but not over items $\left[F_{2}(1,34)=1.14, p<.24\right]$. The interaction of beginning and ending lexeme frequency, which was due to particularly long latencies for LL compounds, was significant over participants $\left[F_{1}(1,29)=19.51, p<.01\right]$ but not over items $\left[F_{2}(1,34)=2.14, p<.16\right]$.

Tailed compounds showed a relatively small beginning lexeme effect, with naming latencies $23 \mathrm{msec}$ longer when the beginning lexeme was a low-frequency word. The difference was reliable over participants $\left[F_{1}(1,29)=10.40\right.$, $p<.01]$ but not over items $\left[F_{2}(1,34)=1.61, p<.22\right]$. Ending lexeme frequency had a much larger influence on naming latencies, with latencies $43 \mathrm{msec}$ longer when the ending lexeme was a low-frequency word $\left[F_{1}(1,29)=\right.$ $\left.47.64, p<.01 ; F_{2}(1,34)=6.98, p<.025\right]$. The interac-

Table 2 Mean Naming Latencies (in Milliseconds) for Experiment 2 As a Function of Compound Type

\begin{tabular}{cccccc}
\multicolumn{4}{c}{ As a Function of Compound Type } \\
\hline \multirow{2}{*}{$\begin{array}{c}\text { Lexeme } \\
\text { Frequency }\end{array}$} & $M$ & $S E$ & & \multicolumn{2}{c}{ Tailed } \\
\cline { 2 - 3 } \cline { 5 - 6 } Headed & & & $S E$ \\
HH & 617 & 17 & 602 & 18 \\
HL & 634 & 19 & 638 & 19 \\
LH & 635 & 18 & & 618 & 20 \\
LL & 693 & 22 & 669 & 20 \\
\hline
\end{tabular}


tion of beginning and ending lexeme frequency was not significant $\left[F_{1}(1,29)=2.26, p<.15 ; F_{2}<1\right]$.

The influence of compound type on the magnitude of beginning and ending lexeme frequency effects, with larger beginning lexeme effects for headed compounds and larger ending lexeme effects for tailed compounds, was also evident in a joint $2 \times 2 \times 2$ analysis that yielded a marginally reliable three-way interaction over participants $\left[F_{1}(1,29)=4.09, p<.053\right]$, but once more no significant effect over items $\left(F_{2}<1\right)$.

\section{Discussion}

The naming latency data of Experiment 2 closely matched the LDT and error data of Experiment 1. Naming responses for headed and tailed compounds were systematically influenced by the word frequencies of the beginning and ending lexemes, and the semantically dominant lexeme yielded a numerically larger word frequency effect. However, the lexeme dominance effect was smaller rather than larger than in Experiment 1; that is, contrary to our expectation, the absence of pseudocompound words did not augment the size and robustness of meaning dominance effects.

Naming latencies can be influenced by the energy release of word-initial phonemes (Balota \& Chumbley, 1985). The different item types were not fully matched on type of onset phoneme, and a supplementary analysis of covariance was conducted to determine whether the robustness of lexeme dominance effects would increase if the influence of phoneme onset variability was considered, under the assumption that phonemes with high energy releases - for example, vowels and plosives - would yield shorter trigger times than consonants with lower energy releases. The results were negative: The three-way interaction of beginning and ending lexeme frequency with compound type was negligible in the items analysis, even when the type of onset phone was included as a covariate in the items analyses $\left(F_{2}<1\right)$. This raises the critical questions of whether and how lexeme dominance influenced compound processing under relatively natural task conditions during silent reading. During normal reading, compound processing is not performed in isolation, and it does not demand the execution of a discriminating overt response.

\section{EXPERIMENT 3} Sentence Reading

\footnotetext{
Method

Participants. Thirty-six State University of New York undergraduates participated for experimental course credit. All participants were native speakers of English and had normal, uncorrected vision. None had previously participated in any aspect of Experiment 1 or 2 .

Materials. The compound targets were identical to those used in Experiments 1 and 2. In addition to the 80 sentences containing compound targets, participants also saw 40 filler sentences and 7 practice sentences (none of which contained a compound word), for a total of 127 sentences. The compound stimuli were embedded in sentence contexts, and none of the sentences exceeded 78 character spaces (including the blank spaces between words). The sentence contexts for compound targets were written by three native speakers
}

of American English. All sentences fulfilled four constraints: The targets never occupied the sentence-initial or sentence-final word location; context preceding a target was relatively neutral; each sentence was devoid of structural ambiguities; and each target was preceded and followed by a word in the midfrequency range, with four or more character constituents.

Apparatus. The stimuli were presented in black on a light gray background on a 21-in. flat-screen monitor using 12-point Courier font. All sentences were shown on a single line of text so that the first letter of each sentence was 10 letter spaces (LSs) to the right of the left screen margin at the vertical midline of the monitor. Eyemonitor distance was set at $90 \mathrm{~cm}$, at which each character of text subtended approximately $0.25^{\circ}$ of visual angle. Sentence viewing was binocular, and the movements of the right eye were recorded with an SR Research Eyelink 1000 tracking system. The head of the reader was supported by a chinrest, and the nonobtrusive sampling of eye position occurred at a rate of $1000 \mathrm{~Hz}$, with a spatial measurement accuracy of approximately one LS. Eyelink software was used to parse the continuously sampled stream of eye locations during sentence reading into fixations and saccades, which were then mapped onto corresponding sentence locations to determine oculomotor activity during compound word reading.

Procedure. The participants were tested individually. A horizontal calibration of the eyetracking system preceded the experiment. During this calibration, each reader was asked to fixate a sequence of four fixation markers as they appeared in random order for $1 \mathrm{sec}$ at the right, left, and center locations of the vertical midline of the screen (the left side location corresponded to the position of the first letter of a sentence). The initial calibration was followed by a validation routine that determined the stability and accuracy of the calibration.

After successful validation, the reader was asked to fixate a marker (a plus sign) at the left side of the screen and to depress a game pad button on a Microsoft game controller. Buttonpressing replaced the marker with a to-be-read sentence and a second fixation marker, the sequence "xxXxx," which was shown five LSs to the right of the sentence period. Buttonpressing also started the recording of eye positions. After a sentence was read, the reader was asked to fixate the center letter of the right-side fixation marker (the " $\mathrm{xxXxx}$ " sequence) and to press the button a second time. This terminated the recording of eye movements for the trial, erased the sentence from the screen, and displayed another left-side fixation marker in order to check calibration accuracy. The location of the fixation on the right-side fixation marker was used to determine whether drift or head movements undermined the accuracy of eyetracking during sentence reading. A recalibration was performed when tracking was inaccurate. Readers were encouraged to read sentences for meaning (i.e., not to skim), and they were asked to repeat or paraphrase the most recently read sentence on about $15 \%$ of the trials. This type of comprehension check has been used in other sentence reading studies (e.g., Rayner, Sereno, \& Raney, 1996). Participants in the present experiment were highly accurate in paraphrasing sentence context (2 participants missed one sentence each).

Design and Data analyses. The following three oculomotor viewing duration measures were computed for analyses: first-fixation durations, consisting of the duration of the first fixation on target words during the sentence's initial (first-pass) reading; gaze durations, consisting of the cumulated viewing time on a target word during its first-pass reading (excluding rereading time); and total viewing durations, consisting of the cumulated time spent looking at target words, including rereading time. Thus, in contrast to first-fixation and gaze durations, total viewing durations included the time spent reading a target word after it may have been identified during first-pass reading. Track losses, instances in which the saccade to the target was larger than $16 \mathrm{LSs}$, and instances in which the first fixation on the target was shorter than $30 \mathrm{msec}$ or longer than 1,000 msec were excluded, which removed $6 \%$ of the data. We also excluded all trials in which the target was skipped ( $9 \%$ of the data), since in those cases it was unclear when identification of the target took place. 
Table 3

First-Fixation Durations, Gaze Durations, and Total Viewing Durations (in Milliseconds) for Experiment 3 As a Function of Compound Type

\begin{tabular}{|c|c|c|c|c|c|c|}
\hline \multirow{2}{*}{$\begin{array}{l}\text { Lexeme } \\
\text { Frequency }\end{array}$} & \multicolumn{2}{|c|}{$\begin{array}{c}\text { First } \\
\text { Fixation }\end{array}$} & \multicolumn{2}{|c|}{ Gaze } & \multicolumn{2}{|c|}{$\begin{array}{c}\text { Total } \\
\text { Viewing }\end{array}$} \\
\hline & $M$ & $S E$ & $M$ & $S E$ & $M$ & $S E$ \\
\hline \multicolumn{7}{|c|}{ Headed Compound } \\
\hline $\mathrm{HH}$ & 272 & 7 & 425 & 16 & 456 & 18 \\
\hline $\mathrm{HL}$ & 248 & 6 & 407 & 18 & 435 & 20 \\
\hline LH & 268 & 10 & 442 & 18 & 480 & 21 \\
\hline LL & 281 & 10 & 469 & 17 & 540 & 24 \\
\hline \multicolumn{7}{|c|}{ Tailed Compound } \\
\hline $\mathrm{HH}$ & 267 & 7 & 395 & 17 & 416 & 18 \\
\hline HL & 278 & 10 & 423 & 18 & 462 & 23 \\
\hline LH & 256 & 9 & 377 & 17 & 397 & 18 \\
\hline LL & 280 & 10 & 441 & 20 & 475 & 23 \\
\hline
\end{tabular}

In addition to these three primary process duration measures, we also computed several movement-related measures: the size of rightdirected saccades that moved the eyes onto a target word, the subsequent landing location on the target, the number of regressions out of a target word, and the number of regressions directed to the target in order to reread it. Beginning and ending lexeme frequency effects were first analyzed for headed and tailed compounds separately. The three viewing duration measures also included a joint analysis of headed and tailed compounds via $2 \times 2 \times 2$ ANOVAs.

\section{Results}

Compound viewing durations. The effects of lexeme frequency and lexeme dominance on first-fixation durations, gaze durations, and total viewing durations are shown in Table 3.

First-fixation durations for headed compounds revealed a sizable beginning lexeme effect of $20 \mathrm{msec}\left[F_{1}(1,35)=\right.$ $4.92, F_{2}(1,36)=4.39$, both $p$ s $\left.<.05\right]$ and a negligible ending lexeme effect of $5 \mathrm{msec}\left(F_{1}\right.$ and $\left.F_{2}<1\right)$. The larger word frequency effect for the beginning than for the end- ing lexeme was also expressed in a reliable interaction $\left[F_{1}(1,35)=9.31, p<.01 ; F_{2}(1,36)=3.91, p<.057\right]$. Tailed compounds, by contrast, showed a negligible 5 -msec beginning lexeme frequency effect $\left(F_{1}\right.$ and $\left.F_{2}<1\right)$ and a sizable ending lexeme effect of $17 \mathrm{msec}[F(1,35)=6.56$, $\left.p<.025 ; F_{2}(1,36)=2.89, p<.098\right]$. The interaction of beginning and ending lexeme effects was, however, not reliable $\left[F_{1}(1,35)=1.82, p<.18 ; F_{2}(1,36)=1.23, p<.28\right]$.

The joint $2 \times 2 \times 2$ ANOVA revealed virtually identical first-fixation durations for headed and tailed compounds (268 msec and $271 \mathrm{msec}$, respectively; $F_{1}$ and $F_{2}<1$ ). It did not yield a reliable three-way interaction $\left[F_{1}(1,35)=\right.$ $2.72, p<.11 ; F_{2}<1$ ], but two two-way interactions with compound type were reliable over participants, though not over items. The beginning lexeme frequency effect was larger for headed compounds $\left[F_{1}(1,35)=5.11, p<\right.$ $\left..05 ; F_{2}(1,72)=2.31, p<.15\right]$, and the ending lexeme effect was larger for tailed compounds $\left[F_{1}(1,35)=4.32\right.$, $\left.p<.05 ; F_{2}(1,72)=2.20, p<.15\right]$. Figure 1 shows the key difference between the HL and LH conditions as a function of compound type; this difference was reliable over participants and items $\left[F_{1}(1,35)=7.12, p<.025\right.$; $\left.F_{2}(1,36)=4.47, p<.05\right]$.

Gaze durations and total viewing durations for headed and tailed compounds yielded corresponding effect patterns. Headed compounds yielded a relatively large beginning lexeme effect for gaze durations $\left[F_{1}(1,35)=\right.$ $\left.13.55, p<.01 ; F_{2}(1,36)=5.23, p<.05\right]$ and for total viewing durations $\left[F_{1}(1,35)=23.97, F_{2}(1,36)=9.92\right.$, both $p \mathrm{~s}<.01]$. The ending lexeme effect was relatively small and was reliable neither for gaze nor for total viewing durations (all $F \mathrm{~s}<1$ ). The larger lexeme frequency effect for the beginning lexeme also yielded an interaction that was reliable over participants for both gaze duration $\left[F_{1}(1,35)=4.56, p<.05 ; F_{2}(1,36)=2.15, p<.16\right]$ and total viewing duration $\left[F_{1}(1,35)=14.27, p<.01\right.$; $\left.F_{2}(1,36)=3.34, p<.07\right]$.

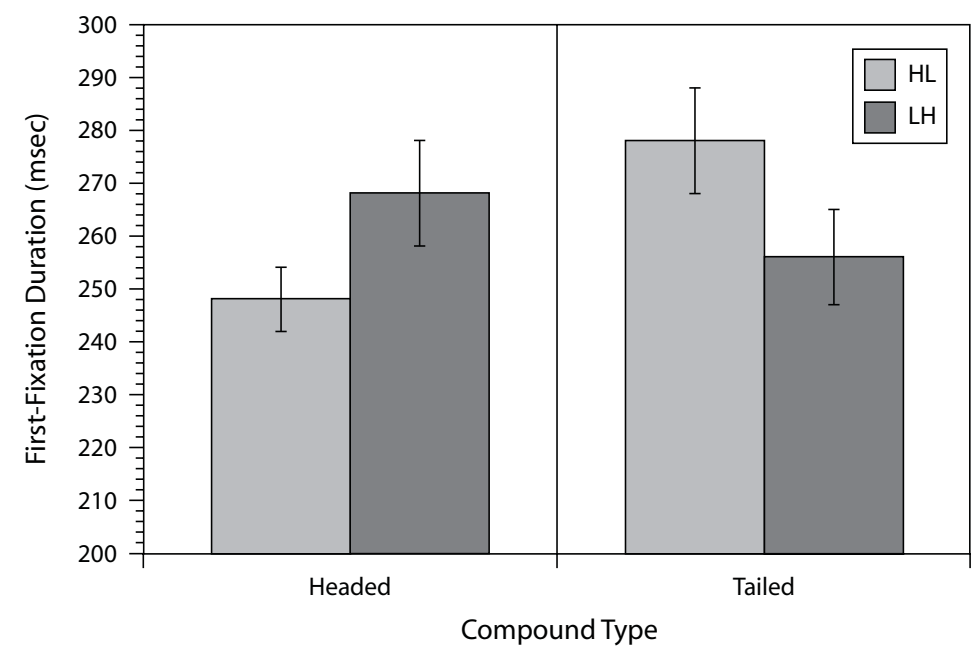

Figure 1. The first-fixation durations for $\mathrm{HL}$ and $\mathrm{LH}$ compounds as a function of compound type. 
Gaze durations and total viewing durations for tailed compounds revealed a reversed effect pattern, with a negligible beginning lexeme effect (all $F_{\mathbf{S}}<1$ ) and a robust ending lexeme effect [for gaze durations, $F_{1}(1,35)=$ $16.92, p<.01 ; F_{2}(1,36)=5.93, p<.025$; for total viewing durations, $F_{1}(1,35)=24.72, F_{2}(1,36)=8.06$, both $p s<.01]$. The interaction of the two lexeme frequency effects was also significant in the participants analysis of gaze durations $\left[F_{1}(1,35)=4.24, p<.05\right]$ and total viewing durations $\left[F_{1}(1,35)=4.41, p<.08\right]$, but not in the corresponding items analysis (both $F_{2} \mathrm{~S} \sim 1$ ).

The joint analysis of beginning and ending lexeme frequency as a function of compound type revealed a robust main effect of compound type, with longer gaze and total viewing durations for headed compounds [respectively, $F_{1}(1,35)=15.25, p<.01 ; F_{2}(1,72)=5.29, p<.025 ;$ and $F_{1}(1,35)=20.11, F_{2}(1,36)=7.41$, both $\left.p \mathrm{~s}<.01\right]$. As in the first-fixation duration data, the combined $2 \times 2 \times 2$ analysis did not reveal a reliable three-way interaction (all $F_{\mathrm{s}}<1$ ), but the beginning lexeme frequency effect was relatively large for headed compounds [for gaze duration, $F_{1}(1,35)=9.21, p<.01 ; F_{2}(1,72)=2.33, p<.15$; for total viewing duration, $F_{1}(1,35)=14.75, p<.01 ; F_{2}(1,72)=$ $5.80, p<.025]$. Conversely, tailed compounds yielded a relatively large ending lexeme effect over participants, though not over items [for gaze duration, $F_{1}(1,35)=5.70$, $p<.025 ; F_{2}(1,72)=1.71, p<.2$; for total viewing duration, $\left.F_{1}(1,35)=3.77, p<.07 ; F_{2}(1,36)=1.18, p<.3\right]$.

Together, the three sets of target viewing data provide converging evidence for the claims that compound words were parsed into constituent lexemes and that lexeme dominance influenced compound recognition. The signature crossover interaction of lexeme dominance with LH and HL compound types was reliable over participants and items for first-fixation durations, indicating that lexeme meaning influenced the initial stage(s) of compound recognition. Target refixations and target rereading, which were included in gaze durations and total viewing durations, respectively, increased the numeric size of the lexeme dominance effect, suggesting that lexeme meaning influenced postlexical processing after the compound was recognized.

Table 4 shows several supplementary oculomotor measures, consisting of the size of right-directed saccades onto a compound word, the letter position of the landing location for these saccades, the relative frequency of regressions of the eye out of a compound, and the relative frequency of regressions back to a compound word after other words in the sentence had been read.

Saccade size and landing position on the target. Although saccades and landing locations are generally related (since a larger saccade will typically move the eyes farther into a word), the launch location of a saccade can vary, and saccade size and landing location data need not fully correspond. In the present study, saccades to headed compounds were $0.5 \mathrm{LSs}$ larger when the beginning lexeme was a high-frequency word $\left[F_{1}(1,35)=18.16, F_{2}(1,36)=\right.$ 9.51 , both $p \mathrm{~s}<.01]$, but this did not result in a corresponding right-directed landing location effect $\left[F_{1}(1,35)=2.14\right.$, $\left.p<.16 ; F_{2} \sim 1\right]$. The frequency of the ending lexeme influenced neither saccade size $\left[F_{1}(1,35)=2.61, p>.11\right.$;
Table 4

Supplementary Movement-Related Reading Measures

\begin{tabular}{|c|c|c|c|c|c|c|c|c|}
\hline \multirow{2}{*}{$\begin{array}{c}\text { Lexical } \\
\text { Frequency }\end{array}$} & \multicolumn{2}{|c|}{$\begin{array}{c}\text { Saccade } \\
\text { Size }\end{array}$} & \multicolumn{2}{|c|}{$\begin{array}{l}\text { Landing } \\
\text { Position }\end{array}$} & \multicolumn{2}{|c|}{$\begin{array}{l}\text { Reg. } \\
\text { Source }\end{array}$} & \multicolumn{2}{|c|}{$\begin{array}{l}\text { Reg. } \\
\text { Target }\end{array}$} \\
\hline & $M$ & $\overline{S E}$ & $M$ & $S E$ & $M$ & $S E$ & $\bar{M}$ & $S E$ \\
\hline \multicolumn{9}{|c|}{ Headed Compound } \\
\hline $\mathrm{HH}$ & 7.2 & 0.2 & 3.8 & 0.2 & 6 & 2 & 5 & 1 \\
\hline HL & 7.4 & 0.2 & 3.7 & 0.1 & 6 & 1 & 7 & 2 \\
\hline LH & 6.7 & 0.2 & 3.4 & 0.2 & 6 & 1 & 8 & 2 \\
\hline LL & 6.9 & 0.2 & 3.6 & 0.2 & 10 & 2 & 8 & 2 \\
\hline \multicolumn{9}{|c|}{ Tailed Compound } \\
\hline $\mathrm{HH}$ & 7.3 & 0.2 & 3.7 & 0.1 & 3 & 1 & 6 & 2 \\
\hline HL & 7.3 & 0.2 & 3.9 & 0.1 & 6 & 1 & 9 & 2 \\
\hline LH & 7.0 & 0.2 & 3.9 & 0.2 & 6 & 1 & 3 & 1 \\
\hline LL & 7.2 & 0.2 & 4.0 & 0.2 & 7 & 1 & 6 & 2 \\
\hline
\end{tabular}

Note-These measures consist of the mean sizes (in letter spaces) of rightdirected saccades onto the target, as well as the letter position that was subsequently fixated, with 0 denoting the blank space preceding the compound. Also shown are the relative frequencies, in percentages, with which a compound word was the source point of a regression to an earlier text segment (Reg. Source) or, in contrast, the target of a regression after one or several words following the compound word had been read (Reg. Target).

$\left.F_{2} \sim 1\right)$ nor landing location $\left(F_{1}\right.$ and $\left.F_{2}<1\right)$. The interaction of beginning and ending frequency was also negligible in both movement measures $\left(F_{1}\right.$ and $\left.F_{2}<1\right)$.

Tailed compounds showed a similar effect pattern, with slightly larger saccades when the beginning lexeme was a high-frequency word, but the effect was reliable for neither the saccade data $\left[F_{1}(1,35)=2.36, p>.13 ; F_{2} \sim 1\right]$ nor the landing location data $\left(F_{1}\right.$ and $\left.F_{2}<1\right)$. The main effect of ending lexeme frequency and the interaction of beginning and ending lexeme frequency were negligible (all $F_{\mathrm{s}} \sim 1$ ). The joint $2 \times 2 \times 2$ ANOVAs revealed only one effect that was reliable over participants and items, with larger incoming saccades when the beginning lexeme of a compound word was a high-frequency word $\left[F_{1}(1,35)=5.13\right.$, $\left.p<.05 ; F_{2}(1,72)=8.18, p<.01\right]$. This effect tended to be larger for headed compounds, but the corresponding interaction was not reliable over items $\left[F_{1}(1,35)=5.12\right.$, $\left.p<.05 ; F_{2}<1\right]$. The joint ANOVA did not reveal a robust effect for landing position.

Regressions. Regressions leaving a headed compound were slightly more common when the beginning lexeme was a low-frequency word, and the corresponding effect was marginally reliable over participants $\left[F_{1}(1,35)=3.50\right.$, $\left.p<.07 ; F_{2}(1,36)=1.57, p<.22\right]$. Regressions leaving the compound were not influenced by the frequency of the ending lexeme $\left(F_{\mathrm{S}}<1\right)$, and the interaction of beginning and ending lexeme frequency was negligible $(F \mathbf{s} \sim 1)$. Headed compounds were also more likely to be the target of a regression when the beginning lexeme was a low-frequency word, although the small numeric effect was not reliable $\left[F_{1}(1,35)=2.42, p<.13 ; F_{2}(1,36)=2.15, p<.16\right]$. The frequency of the ending lexeme and the interaction of the two lexeme frequency effects were not reliable (all $F^{\prime} s \sim 1$ ).

Regressions leaving a tailed compound were a function of neither beginning lexeme frequency $\left[F_{1}(1,35)=2.78\right.$, $\left.p<.11 ; F_{2} \sim 1\right]$ nor ending lexeme frequency $\left[F_{1}(1,35)=\right.$ $\left.2.10, p<.16 ; F_{2} \sim 1\right]$, and the interaction of the two lexeme frequency effects was negligible (all $F \mathrm{~s}<1$ ). Re- 
gressions to tailed compounds were more likely when the beginning lexeme was a low-frequency word $\left[F_{1}(1,35)=\right.$ $\left.6.37, p<.025 ; F_{2}(1,36)=2.15, p<.16\right]$. The effect of the ending lexeme was marginally reliable over participants $\left[F_{1}(1,35)=3.61, p<.07\right]$ but not items $\left(F_{2}<1\right)$. The interaction of the two frequency effects was negligible (all $\left.F_{\mathrm{s}}<1\right)$.

The results of the joint $2 \times 2 \times 2$ analyses were relatively conservative. They did not reveal any reliable interaction with compound type for regressions leaving the target (all $F \mathrm{~s}<1$ ). The analyses of regressions that were directed at compounds yielded one reliable interaction of compound type with beginning lexeme frequency $\left[F_{1}(1,35)=8.47, p<.01 ; F_{2}(1,72)=5.70, p<.025\right]$ : Regressions to headed compounds were more common when the beginning lexeme was a low-frequency word.

\section{Discussion}

The new experimental task did not change the pattern of lexeme frequency and lexeme dominance effects. The time spent viewing compound words during sentence reading was influenced by the word frequencies of a compound's beginning and ending lexemes, and the magnitude of the beginning and ending lexeme effects was a function of compound type. Once more, the effect of word frequency was larger for the dominant lexeme, which had also occurred in Experiments 1 and 2, indicating that effects of lexeme meaning generalize across tasks. Furthermore, the results of Experiment 3 extend the findings of Experiments 1 and 2 in three important respects: First, key effects of lexeme frequency and lexeme dominance were reliable in the first-fixation durations on compound words, indicating that lexeme dominance influenced the initial stages of compound recognition. Second, these effects were generally robust over participants and items when headed and tailed compound words were analyzed separately. Third, lexeme frequency, and in particular the frequency of the beginning lexeme, influenced the rate of regressions in which the eyes returned to the compound word, indicating that some effects of lexeme meaning persisted after a compound word was recognized.

Saccades onto compound words also revealed a robust effect of beginning lexeme frequency, with larger saccades when the beginning lexeme was a high-frequency word. In contrast to this, there was no beginning lexeme frequency effect for incoming saccades in studies with Finnish text (e.g., Hyönä \& Pollatsek, 1998; Pollatsek \& Hyönä, 2005), although one of our earlier experiments with English text (Inhoff et al., 1996, Experiment 2) yielded effects of lexeme structure on the size of incoming saccades. In view of these discrepancies, the effect of beginning lexeme frequency on incoming saccades should be considered with caution, since it could be due to language differences or to some uncontrolled pretarget text properties in our study. However, the saccade effect could also be due to the use of parafoveally available lexical information. The effect of beginning lexeme frequency on the size of incoming saccades was larger for headed compounds, and it may have been missed in earlier studies because those items included few - if any-headed compounds.
The effect of beginning lexeme frequency on the size of saccades to compounds and the interaction of lexeme dominance with beginning and ending lexeme frequency, which was reliable over participants but not over items, also raise the question of whether critical viewing duration effects could have been confounded with visuomotor effects. Detailed inspection of our eye movement data indicates that this is not likely to be the case. The effect of beginning lexeme frequency on saccade size was relatively small (approximately half a letter space), and it is exceedingly unlikely that this had a distinct effect on the integration of information across fixations. Also, lexeme frequency and lexeme type did not influence landing position in any of the analyses, further indicating that there were no differences in the visibility of the two types of compound word once they were fixated. Finally, the slightly larger saccades to headed compounds with high-frequency beginning lexemes were followed by significantly shorter first-fixation durations. If viewing duration effects were due to visuomotor factors, the opposite effect pattern should have emerged, since larger saccades are typically followed by longer fixation durations (see, e.g., Inhoff \& Rayner, 1986; Pollatsek, Rayner, \& Balota, 1986).

\section{GENERAL DISCUSSION}

The signature effect of lexical decomposition of spatially unified compound words - robust influences of the word frequencies of constituent lexemes - was obtained in the present study when compounds were distinguished from pseudocompound items, when they were named, and when they were identified and comprehended during sentence reading. All three experiments are thus in general agreement with earlier work indicating that the orthographic form of a spatially unified compound word is parsed into constituent lexemes during the recognition process.

The present study extends prior research in this domain with three novel findings: In all three experiments, meaning-defining (dominant) lexemes yielded a larger word frequency effect than did nondominant lexemes. Second, the effects of beginning and ending lexeme dominance already emerged during the first fixation on a compound word in the reading task, and third, the frequency of a dominant lexeme, in particular of the beginning lexeme, also influenced the rate of regressions in which the eyes returned to headed compound words. Lexeme meaning thus influenced the recognition and the successful sentence integration of compound words.

The decomposition of the orthographic form of a compound word into less complex constituent forms appears to provide computational advantages. As noted before, less complex forms have a much higher frequency of occurrence than does the full compound form, and they are generally also more familiar than the unified compound. Lamp and (especially) light are, for instance, substantially more common than the unified compound lamplight. The search for a represented word form can thus take advantage of the familiarity of smaller orthographic constituents. It is generally assumed that these smaller constituents are lexemes, although decomposition of compound 
words could also take advantage of the familiarity of other diagnostic letter sequences, as acknowledged by Pollatsek and Hyönä (2005). That is, lexeme frequency effects during compound reading could be one specific instantiation of a more general principle, according to which complex forms are accessed via less complex and more familiar constituent forms.

Letter sequence frequency, on the one hand, and lexeme frequency, on the other, are naturally confounded. One way to determine whether lexeme frequency effects during compound processing derive from the use of constituent lexemes or from the use of familiar letter sequences is to determine whether unique properties of lexemes - for example, their connection to word meaning-influenced compound processing. In all three of our experiments, word frequency effects for the dominant lexeme were larger than word frequency effects for the nondominant lexeme. The presence of sizable lexeme dominance effects across tasks is therefore theoretically significant, in that it provides compelling evidence for the claim that lexemes are used during the recognition of spatially unified compounds. The spatial and conceptual unification of compound words is thus "dissolved" early in the compound recognition process, when a parsing mechanism segments these spatially unified words into viable constituent morphemes (Libben et al., 1999).

Lexeme dominance effects tended to be less robust in the items analyses than in the participants analyses of all three experiments. Marginal, and even negligible, item effects are not uncommon when the materials consist of relatively small item sets and when a relatively conservative between-items design is applied. In spite of these limitations, key lexeme dominance effects were often reliable over participants and items, and the numeric pattern of lexeme dominance effects was consistent across all three experiments. In view of these results, it appears implausible to conclude that our lexeme dominance effects should be considered tentative. Instead, the overall effect pattern was highly consistent, and it favors a view in which lexeme dominance influences compound processing.

Effects of lexeme dominance are novel, but effects of lexeme meaning are not. That is, the semantic transparency and other semantic properties of lexeme constituents influenced semantic priming effects in prior studies that involved the classification of individual target words. Experiments 1 and 2 extended these earlier studies by showing that lexeme meaning influences the processing of individual compound words without the semantic context provided by word primes. Experiment 3 then broke new ground by providing evidence that lexeme meaning contributes to compound recognition during normal reading. This contribution occurs during the early stage(s) of compound recognition, expressed in the effects of beginning and ending lexeme dominance on first-fixation durations, and during relatively late stages when the compound may be integrated into a sentence context, expressed in the influence of beginning lexeme dominance on the rate of regressions toward compound words.

Since the relative contribution of one lexeme meaning to the meaning of the full compound word requires knowledge of the second lexeme, the effects of lexeme dominance on first-fixation durations provide compelling evidence against theoretical conceptions according to which the recognition of solid compounds is strictly serial - that is, that it must proceed from recognition of the first lexeme to recognition of the full compound (Taft, 1994). Instead, serial processing of the constituents of solid compound words appears to occur only when a to-be-recognized compound is relatively long (Bertram \& Hyönä, 2003).

The present findings also disagree with theoretical conceptions in which compound recognition is typically achieved by using either constituent lexemes or the whole word form for lexical access. Baayen, Dijkstra, and Schreuder (1997) suggested, for instance, that complex words can be accessed by independent lexeme and fullword-form routes that race against each other. Although this theoretical conception can account for beginning and ending lexeme frequency effects and for the effects of full compound forms that have been obtained in other studies, it cannot account for the interaction of lexeme frequency effects with lexeme dominance effects. That is, if the race of lexeme forms and full word forms for recognition were independent, the relative contribution of a lexeme constituent to compound recognition could not depend on properties of the full compound word - that is, whether it is headed or tailed - as was the case in all three experiments of the present study.

The results of these three experiments are consistent, however, with theoretical conceptions in which compound processing involves the interactive use of lexemes and full word forms (Taft, 1994). In Taft's model, morphemic units activate a cohort of compatible words, and the activated full word forms increase the activation level of their constituents via feedback connections. The full compound can thus influence the level of activation of its constituent lexemes, and this feedback should provide more benefit to the dominant than to the nondominant constituent lexeme, especially when the experimental task requires the use of compound meaning - hence, the robustness of lexeme dominance effects in the sentence reading task.

Lexeme and compound word meanings can be unrelated, however, as occurs with opaque and partially opaque compounds. ${ }^{2}$ Yet, even in these cases, a semantic relationship often exists between an opaque lexeme and its compound. Even though the lexeme bird of jailbird typically refers to a person rather than an animal, it can convey useful semantic information, such as being caged or wishing to fly free. Therefore, one plausible account for the absence of lexeme meaning effects in earlier work has been that readers interpreted opaque lexemes metaphorically. From this perspective, the specification of compound meaning in reading can be seen as a special case in which the semantic properties of consecutive words are combined and refined so that they form-and conform to - an overarching meaning representation.

\section{AUTHOR NOTE}

Research on this project was supported by NIH Grant HD043405. We thank Craig Mathews for his help with the testing of participants and Barbara Juhasz, Keith Rayner, Alexander Pollatsek, Françoise 
Vitu, and an anonymous reviewer for their helpful comments on an earlier version of the manuscript. M.S.S. is now employed by IBM Corporation, and L.P. by Bosch Corporation. Correspondence relating to this article may be sent to A. W. Inhoff, Department of Psychology, State University of New York, Binghamton, NY 13902-6000 (e-mail inhoff@binghamton.edu).

\section{REFERENCES}

Andrews, S., Miller, B., \& Rayner, K. (2004). Eye movements and morphological segmentation of compound words: There is a mouse in mousetrap. European Journal of Cognitive Psychology, 16, 285-311.

BAayen, R. H., Dijkstra, T., \& Schreuder, R. (1997). Singulars and plurals in Dutch: Evidence for a parallel dual-route model. Journal of Memory \& Language, 37, 94-117.

BAlota, D. A., \& ChUmbley, J. I. (1985). The locus of word-frequency effects in the pronunciation task: Lexical access and/or production? Journal of Memory \& Language, 24, 89-106.

Bertram, R., \& HyöNÄ, J. (2003). The length of a complex word modifies the role of morphological structure: Evidence from eye movements when reading short and long Finnish compounds. Journal of Memory \& Language, 48, 615-634.

CoOlen, R., van JAARSVeld, H. J., \& Schreuder, R. (1991). The interpretation of isolated novel nominal compounds. Memory \& Cognition, 19, 341-352.

Coolen, R., van JaArsveld, H. J., \& Schreuder, R. (1993). Processing novel compounds: Evidence for interactive meaning activation of ambiguous nouns. Memory \& Cognition, 21, 235-246.

Frisson, S., Niswander-Klement, E., \& Pollatsek, A. (2008). The role of semantic transparency in the processing of English compound words. British Journal of Psychology, 99, 87-107.

HyöNÄ, J., \& PollatseK, A. (1998). Reading Finnish compound words: Eye fixations are affected by component morphemes. Journal of Experimental Psychology: Human Perception \& Performance, 24, 1612-1627.

Inhoff, A. W., Brithl, D., \& Schwartz, J. (1996). Compound word effects differ in reading, on-line naming, and delayed naming tasks. Memory \& Cognition, 24, 466-476.

InHOFF, A. W., RADACH, R., \& Heller, D. (2000). Complex compounds in German: Interword spaces facilitate segmentation but hinder assignment of meaning. Journal of Memory \& Language, 42, 23-50.

InHOFF, A. W., \& RaYNer, K. (1986). Parafoveal word processing during eye fixations in reading: Effects of word frequency. Perception \& Psychophysics, 40, 431-439.

INHOFF, A. W., \& Topolski, R. (1994). Seeing morphemes: Loss of visibility during the retinal stabilization of compound and pseudocompound words. Journal of Experimental Psychology: Human Perception \& Performance, 20, 840-853.

Jarema, G., Busson, C., Nikolova, R., Tsapkini, K., \& Libben, G. (1999). Processing compounds: A cross-linguistic study. Brain \& Language, 68, 362-369.

JuHAsz, B. J. (2007). The influence of semantic transparency on eye movements during English compound word recognition. In R. P. G. van Gompel, M. H. Fischer, W. S. Murray, \& R. L. Hill (Eds.), Eye movements: A window on mind and brain (pp. 373-389). Amsterdam: Elsevier.

Juhasz, B. J., Inhoff, A. W., \& RAYNeR, K. (2005). The role of interword spaces in the processing of English compound words. Language \& Cognitive Processes, 20, 291-316.

Juhasz, B. J., Starr, M. S., Inhoff, A. W., \& Placke, L. (2003). The effects of morphology on the processing of compound words: Evidence from naming, lexical decisions and eye fixations. British Journal of Psychology, 94, 223-244.

Laudanna, A., Badecker, W., \& Caramazza, A. (1989). Priming homographic stems. Journal of Memory \& Language, 28, 531-546.

Libben, G., Derwing, B. L., \& De Almeida, R. G. (1999). Ambiguous novel compounds and models of morphological parsing. Brain \& Language, 68, 378-386.

Libien, G., Gibson, M., Yoon, Y. B., \& Sandra, D. (2003). Compound fracture: The role of semantic transparency and morphological headedness. Brain \& Language, 84, 50-64.

Lima, S. D., \& PollatseK, A. (1983). Lexical access via an orthographic code? The Basic Orthographic Syllabic Structure (BOSS) reconsidered. Journal of Verbal Learning \& Verbal Behavior, 22, 310-332.
PollatseK, A., \& HYÖNÄ, J. (2005). The role of semantic transparency in the processing of Finnish compound words. Language \& Cognitive Processes, 20, 261-290.

PollatseK, A., Hyönä, J., \& Bertram, R. (2000). The role of morphological constituents in reading Finnish compound words. Journal of Experimental Psychology: Human Perception \& Performance, 26, 820-833.

Pollatsek, A., Rayner, K., \& Balota, D. A. (1986). Inferences about eye movement control from the perceptual span in reading. Perception \& Psychophysics, 40, 123-130.

Prinzmetal, W. (1990). Neon colors illuminate reading units. Journal of Experimental Psychology: Human Perception \& Performance, 16, 584-597.

Prinzmetal, W., Hoffman, H., \& Vest, K. (1991). Automatic processes in word perception: An analysis from illusory conjunctions. Journal of Experimental Psychology: Human Perception \& Performance, 17, 902-923.

RAYNer, K., \& Fischer, M. H. (1996). Mindless reading revisited: Eye movements during reading and scanning are different. Perception \& Psychophysics, 58, 734-747.

RAYNer, K., \& RANEY, G. E. (1996). Eye movement control in reading and visual search: Effects of word frequency. Psychology Bulletin \& Review, 3, 245-248.

RAYNER, K., SERENO, S. C., \& RANEy, G. E. (1996). Eye movement control in reading: A comparison of two types of models. Journal of Experimental Psychology: Human Perception \& Performance, 22, 1188-1200.

SANDRA, D. (1990). On the representation and processing of compound words: Automatic access to constituent morphemes does not occur. Quarterly Journal of Experimental Psychology, 42A, 529-567.

SHILlCock, R. (1990). Lexical hypotheses in continuous speech. In G. T. M. Altmann (Ed.), Cognitive models of speech processing: Psycholinguistic and computational perspectives (pp. 24-49). Cambridge, MA: MIT Press.

TAFT, M. (1985). The decoding of words in lexical access: A review of the morphographic approach. In D. Besner, T. G. Waller, \& G. E. MacKinnon (Eds.), Reading research: Advances in theory and practice (Vol. 5, pp. 83-124). Orlando: Academic Press.

TAFT, M. (1994). Interactive-activation as a framework for understanding morphological processing. Language \& Cognitive Processes, 9 , 271-294.

TAFT, M., \& FoRSTER, K. I. (1976). Lexical storage and retrieval of polymorphemic and polysyllabic words. Journal of Verbal Learning \& Verbal Behavior, 15, 607-620.

van JAARSveld, H. J., \& RattinK, G. E. (1988). Frequency effects in the processing of lexicalized and novel nominal compounds. Journal of Psycholinguistic Research, 17, 447-473.

ZWITSERLOOD, P. (1994). The role of semantic transparency in the processing and representation of Dutch compounds. Language \& Cognitive Processes, 9, 341-368.

\section{NOTES}

1. This definition differs somewhat from the traditional definition utilized by linguists, wherein the semantic "head" of a compound is its ending lexeme (typically the meaning-defining lexeme). Although some confusion may result from our use of the term headed, we consider our choice of terms to be more descriptive.

2 . We sought to avoid opaque or partially opaque compound constructions but, because of the large number of constraints on item selection, were not always successful. The second lexeme is relatively opaque in the headed HL and LH compounds homestead, nightmare, sideburns, and boldface. Similarly, the first lexeme is opaque in the tailed compounds nickname, stepmother, stepchild, handmaiden, and stockcar. Lexeme dominance effects thus could emerge primarily when a dominant transparent lexeme is accompanied by a nondominant opaque lexeme. To examine this possibility, we removed these nine items from the items analysis of headed and tailed HL and LH compounds. Although this reduced the relatively small set of items, the critical interaction of lexeme type (HL vs. LH) with compound type (headed vs. tailed) was marginally reliable in the first-fixation durations and gaze durations $\left[F_{2}(1,27)=\right.$ $2.94, p<.098$, and $F_{2}(1,27)=2.61, p<.12$, respectively] and reliable in the total viewing durations $\left[F_{2}(1,27)=4.51, p<.05\right]$. Lexeme dominance effects thus do not appear to depend on the opaqueness of the nondominant lexeme. 
APPENDIX

\begin{tabular}{|c|c|c|c|c|c|c|c|}
\hline Dominance & $\begin{array}{l}\text { Lexeme } 1 \\
\text { Frequency }\end{array}$ & $\begin{array}{l}\text { Lexeme } 2 \\
\text { Frequency }\end{array}$ & Word & LDT & Naming & $\begin{array}{c}\text { First } \\
\text { Fixation }\end{array}$ & Gaze \\
\hline Headed & $\mathrm{H}$ & $\mathrm{H}$ & deathbed & 820.087 & 674.8214 & 309.1818 & 462.5758 \\
\hline Headed & $\mathrm{H}$ & $\mathrm{H}$ & hairpiece & 637.9032 & 577.8667 & 256.4194 & 478.3871 \\
\hline Headed & $\mathrm{H}$ & $\mathrm{H}$ & humankind & 638.1613 & 680.0385 & 300.1875 & 396.2188 \\
\hline Headed & $\mathrm{H}$ & $\mathrm{H}$ & mouthpiece & 654.8387 & 583.9333 & 248.1333 & 384.7667 \\
\hline Headed & $\mathrm{H}$ & $\mathrm{H}$ & powerhouse & 603 & 582.2667 & 256.8824 & 389.3529 \\
\hline Headed & $\mathrm{H}$ & $\mathrm{H}$ & riverbed & 773.1379 & 583.9333 & 278.2581 & 458.1935 \\
\hline Headed & $\mathrm{H}$ & $\mathrm{H}$ & seafront & 721.8519 & 597.5357 & 266.3214 & 439.8571 \\
\hline Headed & $\mathrm{H}$ & $\mathrm{H}$ & shorthand & 619.0645 & 627.3667 & 251.7419 & 368.0645 \\
\hline Headed & $\mathrm{H}$ & $\mathrm{H}$ & waterfront & 597 & 626.7 & 281.6 & 474.8667 \\
\hline Headed & $\mathrm{H}$ & $\mathrm{H}$ & womankind & 620.069 & 648.4 & 259.6786 & 407.9286 \\
\hline Headed & $\mathrm{H}$ & $\mathrm{L}$ & bloodshed & 678.6667 & 625.3214 & 242.4516 & 376.5161 \\
\hline Headed & $\mathrm{H}$ & $\mathrm{L}$ & heartbeat & 721.2667 & 598.6071 & 257.7742 & 437.1935 \\
\hline Headed & $\mathrm{H}$ & $\mathrm{L}$ & homestead & 685.3871 & 608.8621 & 260.1 & 465.8 \\
\hline Headed & $\mathrm{H}$ & $\mathrm{L}$ & motherhood & 630.1613 & 563.069 & 223.1212 & 361.5758 \\
\hline Headed & $\mathrm{H}$ & $\mathrm{L}$ & newsflash & 704.9677 & 653.3793 & 287.2903 & 391.5806 \\
\hline Headed & $\mathrm{H}$ & $\mathrm{L}$ & nightmare & 680.6774 & 552.2667 & 245.9259 & 312.6667 \\
\hline Headed & $\mathrm{H}$ & $\mathrm{L}$ & playwright & 676.0968 & 657.7 & 259.5882 & 393.3529 \\
\hline Headed & $\mathrm{H}$ & $\mathrm{L}$ & sideburns & 714.9032 & 648.3333 & 229.9333 & 422.5 \\
\hline Headed & $\mathrm{H}$ & $\mathrm{L}$ & windowpane & 821.7692 & 712.3214 & 271.9688 & 519.75 \\
\hline Headed & $\mathrm{H}$ & $\mathrm{L}$ & windowsill & 753.3929 & 689.1724 & 237.3 & 431.5667 \\
\hline Headed & $\mathrm{L}$ & $\mathrm{H}$ & boldface & 704.4286 & 625 & 262.5714 & 383.3929 \\
\hline Headed & $\mathrm{L}$ & $\mathrm{H}$ & campground & 737.0323 & 583.5556 & 251.2258 & 492.8387 \\
\hline Headed & $\mathrm{L}$ & $\mathrm{H}$ & choirboy & 781.6364 & 786.9524 & 245.1333 & 514.4333 \\
\hline Headed & $\mathrm{L}$ & $\mathrm{H}$ & dreamland & 684.0968 & 627.3571 & 248.5 & 396.1333 \\
\hline Headed & $\mathrm{L}$ & $\mathrm{H}$ & guidebook & 617.4194 & 559.2667 & 267.0625 & 446.3438 \\
\hline Headed & $\mathrm{L}$ & $\mathrm{H}$ & masthead & 935.4545 & 709.2963 & 323.3448 & 465.931 \\
\hline Headed & $\mathrm{L}$ & $\mathrm{H}$ & noblewoman & 759.069 & 668.8621 & 312.1786 & 484.25 \\
\hline Headed & $\mathrm{L}$ & $\mathrm{H}$ & staircase & 605 & 550.1724 & 229.0645 & 316.3871 \\
\hline Headed & $\mathrm{L}$ & $\mathrm{H}$ & swordplay & 802.2143 & 631.913 & 312.9643 & 483.6786 \\
\hline Headed & $\mathrm{L}$ & $\mathrm{H}$ & wrongdoing & 819.96 & 652 & 265.8 & 412.3667 \\
\hline Headed & $\mathrm{L}$ & $\mathrm{L}$ & litterbug & 748.5926 & 616.6667 & 273.125 & 505.5 \\
\hline Headed & $\mathrm{L}$ & $\mathrm{L}$ & loonybin & 1021.909 & 801.32 & 279.6552 & 483.0345 \\
\hline Headed & $\mathrm{L}$ & $\mathrm{L}$ & maidenhood & 842.5 & 706.7931 & 295.56 & 542.96 \\
\hline Headed & $\mathrm{L}$ & $\mathrm{L}$ & ovenware & 843.75 & 751.0357 & 346.2593 & 465.2963 \\
\hline Headed & $\mathrm{L}$ & $\mathrm{L}$ & scapegoat & 742.5172 & 687.8621 & 267.1935 & 425.6452 \\
\hline Headed & $\mathrm{L}$ & $\mathrm{L}$ & shoehorn & 846.7778 & 636.1429 & 305.6522 & 464.1304 \\
\hline Headed & $\mathrm{L}$ & $\mathrm{L}$ & stairwell & 639.9 & 585.4667 & 268.4063 & 380.9063 \\
\hline Headed & $\mathrm{L}$ & $\mathrm{L}$ & striptease & 765.9655 & 686.4643 & 260.7419 & 513.3226 \\
\hline Headed & $\mathrm{L}$ & $\mathrm{L}$ & swineherd & 784.7143 & 747.7586 & 274.52 & 475.6 \\
\hline Headed & $\mathrm{L}$ & $\mathrm{L}$ & tearjerker & 790.4762 & 669.0714 & 269.8065 & 475.871 \\
\hline Tailed & $\mathrm{H}$ & $\mathrm{H}$ & airfield & 727.5385 & 623.8929 & 268.2593 & 391.4444 \\
\hline Tailed & $\mathrm{H}$ & $\mathrm{H}$ & armchair & 659.9677 & 559.1034 & 246.9688 & 401.125 \\
\hline Tailed & $\mathrm{H}$ & $\mathrm{H}$ & handbook & 611.0333 & 581.2857 & 306.2258 & 399.6129 \\
\hline Tailed & $\mathrm{H}$ & $\mathrm{H}$ & headlight & 651 & 546.7 & 270.5294 & 321.7353 \\
\hline Tailed & $\mathrm{H}$ & $\mathrm{H}$ & housewife & 601.3667 & 562.8214 & 233.4545 & 395.303 \\
\hline Tailed & $\mathrm{H}$ & $\mathrm{H}$ & mainland & 619.6129 & 588.1034 & 262.4828 & 383.2759 \\
\hline Tailed & $\mathrm{H}$ & $\mathrm{H}$ & schoolgirl & 679.2333 & 600.3 & 237.4688 & 352.0313 \\
\hline Tailed & $\mathrm{H}$ & $\mathrm{H}$ & stateroom & 823.2 & 656.3793 & 296.5 & 430.3929 \\
\hline Tailed & $\mathrm{H}$ & $\mathrm{H}$ & streetcar & 698.7241 & 699.75 & 281.1818 & 503 \\
\hline Tailed & $\mathrm{H}$ & $\mathrm{H}$ & summerhouse & 665.8065 & 597.1724 & 278.9118 & 409.1176 \\
\hline Tailed & $\mathrm{H}$ & $\mathrm{L}$ & airbrake & 851.9231 & 580.9667 & 257.3333 & 371.0909 \\
\hline Tailed & $\mathrm{H}$ & $\mathrm{L}$ & bloodhound & 696.5484 & 646.4138 & 288.1613 & 469.2903 \\
\hline Tailed & $\mathrm{H}$ & $\mathrm{L}$ & earthworm & 659.7667 & 621.6667 & 272.3214 & 426.6786 \\
\hline Tailed & $\mathrm{H}$ & $\mathrm{L}$ & fireflies & 771.9355 & 608.8667 & 265.5938 & 433.1563 \\
\hline Tailed & $\mathrm{H}$ & $\mathrm{L}$ & handcart & 830.381 & 659.3571 & 245.129 & 402.2903 \\
\hline Tailed & $\mathrm{H}$ & $\mathrm{L}$ & handmaiden & 868.2727 & 824.6667 & 294.75 & 469.1786 \\
\hline Tailed & $\mathrm{H}$ & $\mathrm{L}$ & headwind & 784.4583 & 598 & 264.0833 & 366.5833 \\
\hline Tailed & $\mathrm{H}$ & $\mathrm{L}$ & sunbonnet & 837.7368 & 706.28 & 300.7143 & 459.1429 \\
\hline Tailed & $\mathrm{H}$ & $\mathrm{L}$ & tablespoon & 649.8276 & 583.8966 & 284.7059 & 414.8824 \\
\hline Tailed & $\mathrm{H}$ & $\mathrm{L}$ & watermelon & 661.7097 & 585.6552 & 253.4848 & 394.7576 \\
\hline Tailed & $\mathrm{L}$ & $\mathrm{H}$ & briefcase & 669.1034 & 597.8214 & 242.3939 & 324.8788 \\
\hline Tailed & $\mathrm{L}$ & $\mathrm{H}$ & deckchair & 767.3913 & 630.3929 & 266.9 & 502.7667 \\
\hline Tailed & $\mathrm{L}$ & $\mathrm{H}$ & flashlight & 653.1935 & 567.1333 & 227.4722 & 348.8889 \\
\hline Tailed & $\mathrm{L}$ & $\mathrm{H}$ & floodlight & 738.1935 & 665.5 & 274.5667 & 383.7 \\
\hline Tailed & $\mathrm{L}$ & $\mathrm{H}$ & motorcar & 701.9333 & 624.5862 & 238.9091 & 361.5152 \\
\hline Tailed & $\mathrm{L}$ & $\mathrm{H}$ & nickname & 682.6774 & 607.6296 & 229.6061 & 270.6364 \\
\hline Tailed & $\mathrm{L}$ & $\mathrm{H}$ & pinpoint & 659.7 & 641.7857 & 289.2813 & 371.1563 \\
\hline Tailed & L & $\mathrm{H}$ & stepchild & 709.7241 & 640.5 & 294.2903 & 473.4839 \\
\hline Tailed & $\mathrm{L}$ & $\mathrm{H}$ & stepmother & 649.9355 & 571.5172 & 252.0606 & 360.8485 \\
\hline
\end{tabular}


APPENDIX (Continued)

\begin{tabular}{lcclllll}
\hline & Lexeme 1 & Lexeme 2 & & & \multicolumn{1}{c}{ First } \\
Dominance & Frequency & Frequency & \multicolumn{1}{c}{ Word } & \multicolumn{1}{c}{ LDT } & Naming & Fixation & Gaze \\
\hline Tailed & L & H & stockcar & 839.6364 & 625.5333 & 283.5806 & 434.129 \\
Tailed & L & L & bobsleigh & $1,025.4$ & 778.75 & 345.0909 & 482.4091 \\
Tailed & L & L & peppermint & 620.6129 & 601.5517 & 273.5429 & 405.8 \\
Tailed & L & L & photocopier & 710.9677 & 738.25 & 268.3226 & 452.3548 \\
Tailed & L & L & pinstripe & 763 & 651.2222 & 263.8667 & 397.3667 \\
Tailed & L & L & rattlesnake & 743.5806 & 580.8 & 250.0333 & 451.4333 \\
Tailed & L & L & reindeer & 792.1613 & 709.1724 & 295.2759 & 434.5517 \\
Tailed & L & L & sourdough & 752.931 & 654.2692 & 281.2333 & 480.4333 \\
Tailed & L & L & spearmint & 734.2143 & 693.4 & 296.875 & 491.7813 \\
Tailed & L & L & switchblade & 776 & 655.0741 & 265.0938 & 466.3438 \\
Tailed & L & L & whirlwind & 754.6552 & 645.8667 & 271.0625 & 344.4063 \\
\hline
\end{tabular}

Note-All times are measured in milliseconds. LDT, lexical decision time.

(Manuscript received June 2, 2007;

revision accepted for publication October 1, 2007.) 